\title{
Effects of Proactive Behavior on Within-Day Changes in Occupational Well-Being: the Role of Organizational Tenure and Emotion Regulation Skills
}

\author{
Clarissa Bohlmann ${ }^{1}$ (D) $\cdot$ Cort W. Rudolph ${ }^{2}$ (D) Hannes Zacher $^{1}$ (D)
}

Received: 9 May 2020 /Revised: 11 April 2021 / Accepted: 29 April 2021/

Published online: 18 May 2021

(C) The Author(s) 2021

\begin{abstract}
Research has recently started to examine relationships between proactive behavior and employee well-being. Investigating these relationships is important to understand the effects of proactive behavior at work, and whether proactive behavior leads to an increase or a decrease in well-being. In this daily-diary study, we investigated effects of proactive behavior on within-day changes in four indicators of occupational well-being (i.e., activated positive and negative affect, emotional work engagement and fatigue). Moreover, based on the meta-concept of wise proactivity, which suggests that proactive behavior may lead to either favorable or unfavorable consequences depending on certain boundary conditions, we examined organizational tenure and emotion regulation skills as moderators of these effects. In total, $N=71$ employees participated in a daily-diary study with two measurements per day for ten consecutive working days. Results showed that emotion regulation skills interacted with proactive behavior to predict within-day changes in emotional work fatigue, such that the effect of proactive behavior on emotional work fatigue was only positive for employees with low (vs. high) emotion regulation skills. Supplementary analyses examining reverse effects of occupational well-being on proactive behavior showed that organizational tenure interacted with activated positive and negative affect in predicting within-day changes in proactive behavior. For employees with lower (vs. higher) organizational tenure, both activated positive and negative affect were negatively associated with proactive behavior. Overall, our findings contribute to the growing body of research on proactive behavior and well-being by demonstrating reciprocal and conditional day-level relationships among these variables.
\end{abstract}

Keywords Proactivity $\cdot$ Wise $\cdot$ Well-being $\cdot$ Daily-diary study $\cdot$ Within-person

Clarissa Bohlmann

clarissa.bohlmann@uni-leipzig.de

Extended author information available on the last page of the article 
Owing in part to increasingly uncertain, complex, and interdependent work environments, organizations are more often calling for initiative from their employees to augment effective task performance (Frese, 2000; Griffin et al., 2007; Parker \& Bindl, 2017). Researchers often refer to such initiative as proactive behavior, which has been defined as self-starting and future-oriented actions to change and improve the work environment or oneself (Grant \& Ashford, 2008; Parker et al., 2006). Examples of proactive behaviors include anticipating problems and preventing their occurrence, or actively seeking feedback from others (Crant, 2000; Frese \& Fay, 2001). Due to the positive association between proactive behavior and performance outcomes, most research has focused on the individual and contextual variables that predict proactive behavior, such as personality or job design (Bindl \& Parker, 2012).

Comparatively less research has investigated the psychological consequences of proactive behavior at work and, in particular, its associations with well-being outcomes (for reviews, see Cangiano et al., 2017; Cangiano \& Parker, 2016). Based on selfdetermination theory, Strauss and Parker (2014) proposed that proactive behavior can positively influence employee well-being by meeting basic human needs, such as the need for autonomy. Other researchers have also suggested that proactive behavior can deplete regulatory resources and, in turn, lead to job strain (Bolino et al., 2010). Cangiano and Parker (2016) further argued that the short-term (i.e., within-person) influence of proactive behavior on well-being may not only occur through a resourcegeneration pathway (based on self-determination theory; Gagné \& Deci, 2005) but, due to the necessary investment of energy resources when engaging in proactive behavior, also a resource-depletion pathway (based on conservation of resources theory; Hobfoll, 1989). Proactive behavior would thus, according to the model by Cangiano and Parker (2016), lead to positive or negative well-being outcomes depending on different moderators. In the present study, we investigate the effects of proactive behavior on within-day changes in well-being. More specifically, we consider two positive and two negative well-being consequences of proactive behavior, namely activated positive affect and emotional work engagement, as well as activated negative affect and emotional work fatigue, respectively.

A more recent stream of research has further focused on the meta-theoretical notion of wise proactivity. Wise proactivity is a meta-theoretical concept (i.e., it is not a specific, measurable construct) that explains an expected pattern of relationships between proactive behavior and other variables. This meta-concept was developed by Parker et al. (2019) in an attempt to account for the observation that proactive behavior may have both positive and negative consequences for other people, the organization, or those who enact it, and that these favorable or unfavorable outcomes of proactive behavior may depend on certain boundary conditions, including characteristics of the employee or their work environment (Parker \& Wang, 2015). In their review of moderating factors that may strengthen the effects of proactive behavior on favorable outcomes, Parker et al. (2019) identify contextual knowledge (e.g. regarding the work environment), person-organization fit, and emotion regulation skills as crucial.

Based on these theoretical considerations, we investigate organizational tenure and emotion regulation skills as potential moderators of the effects of proactive behavior on within-day changes in occupational well-being outcomes in our study. First, we focus on organizational tenure, because longer tenure may help employees to tailor their behavior to the organizational context by using knowledge they have gained via 
experience (e.g., understanding how colleagues think and feel), thereby increasing their person-organization fit. Both knowledge of the work environment and personorganization fit were identified as crucial factors by Parker et al. (2019), suggesting that organizational tenure may be an important factor that strengthens the effects of proactive behavior on occupational well-being outcomes. Second, we focus on emotion regulation skills, which were identified as crucial by Parker et al. (2019), because these skills may help employees' focus on proactive events and improve their coping efforts to deal with emotional events associated with proactive behavior. We focus on withinperson relationships and investigate whether these two between-person moderators (e.g., organizational tenure and emotion regulation skills) influence the direction and strength of effects of proactive behavior during the first half of the workday on withinday changes in positive or negative well-being between midday and late afternoon (i.e., time lagged effects). In other words, we propose that intraindividual differences in organizational tenure and emotion regulation skills moderate the effects of proactive behavior on within-day changes in well-being outcomes.

It is important to note that although wise proactivity is not directly measurable, it provides an important meta-concept that helps to understand why these two variables may moderate the relationship between proactive behavior and occupational wellbeing. More specifically, higher organizational tenure might strengthen the relationship between proactive behavior and within-day changes in positive well-being outcomes by supporting proactive behavior, as it provides an inherent understanding of how and when proactive behavior may fit the overall organizational culture, and thus reaching one's goals. On the contrary, lower organizational tenure may weaken the relationship between proactive behavior and within-day changes in positive well-being outcomes, as individuals with low organizational tenure may not be able to correctly judge the adequacy of proactive behavior. Higher levels of emotion regulation skills, on the other hand, can help to address situations that may arise when engaging in proactive behavior, such as channeling setbacks into positive emotions throughout the proactive process. Lower levels of emotion regulation skills may, on the contrary, not allow for an effective regulation of emotions during the proactive process and thus weaken the relationship between proactive behavior and within-day changes in positive well-being outcomes. Our conceptual model is shown in Fig. 1.

Our results contribute to the literature on proactive behavior in three important ways. First, research has only recently begun to consider directional effects of proactive behavior on well-being at work (Cangiano et al., 2018; Liu et al., 2019). In addition, research on the effects of proactive behavior on well-being at work has mostly focused on either positive or negative well-being outcomes (for a review see Cangiano \& Parker, 2016). This perspective, however, is limited, as well-being encompasses a broader spectrum of both positive and negative experiences (Sonnentag, 2015; Wright \& Cropanzano, 2000). Thus, focusing on both positive and negative wellbeing outcomes of proactive behavior, is important to gain a more complete understanding of the psychological consequences of proactive behavior as proposed in the theoretical model by Cangiano and Parker (2016).

Second, to contribute to an enhanced understanding of the short-term (i.e., withinday) well-being consequences of proactive behavior, our study employs a daily-diary design with two assessments per day, across ten working days. Although within-person designs focusing on changes in proactive behavior and well-being during the day have 


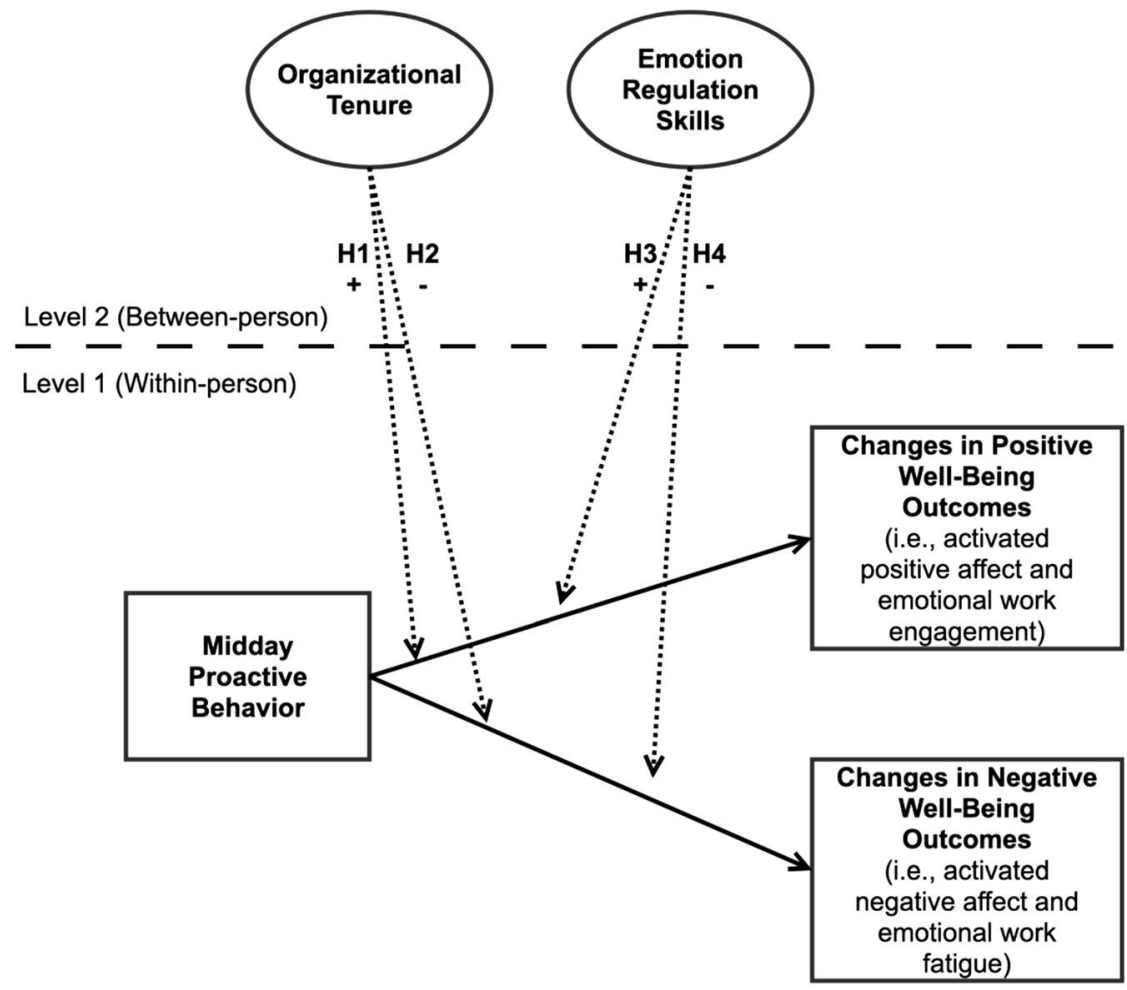

Fig. 1 Conceptual Model. Note. Dotted lines indicate cross-level moderation effects of organizational tenure and emotion regulation skills. Changes in well-being outcomes reflect midday to late afternoon changes

often been employed to investigate antecedents of proactive behavior (e.g., Sonnentag, 2003; Sonnentag et al., 2010), few studies have used such designs to investigate outcomes of proactive behavior (see Cangiano et al., 2018; Fay \& Hüttges, 2016 for exceptions). Moreover, although meta-analyses imply that proactive behavior may have a positive impact on well-being at the between-person level of analysis (Thomas et al., 2010), these relationships could differ at the within-person level (Parker et al., 2019). For example, well-being often fluctuates over relatively short time-periods (e.g., within-day). This makes within-person designs a more appropriate approach to understand well-being outcomes of proactive behavior (Xanthopoulou et al., 2012), as they can also account for the time-lag between proactive behavior and well-being outcomes (e.g., to investigate within-day effects of proactive behavior during the first half of the workday on positive or negative well-being outcomes at the end of the workday).

Third, Cangiano and Parker (2016) suggested that “...proactivity is likely to affect mental health and well-being in multiple ways, and [...] moderating variables and mediating processes need to be considered..." (p. 229). Although a few empirical studies have investigated individual and contextual factors, such as supervisory behavior or organizational support, as moderators of the effect of proactive behavior on wellbeing outcomes (e.g., Cangiano et al., 2018; Zacher et al., 2019), theory-based knowledge of the boundary conditions of the relationship between proactive behavior and 
well-being outcomes is still limited. By examining potential cross-level interactions of proactive behavior with organizational tenure and emotion regulation skills on withinday changes in well-being outcomes consistent with the meta-concept of wise proactivity, our findings contribute to a broader understanding of the boundary conditions of proactivity-well-being links, as well as the emerging literature on wise proactivity (Parker et al., 2019).

\section{Occupational Well-Being}

We examine two sets of well-being outcomes in this study. First, we examine the effects of proactive behavior on within-day changes in positive well-being indicators, namely activated positive affect and emotional engagement at work. Affect is an "... umbrella term encompassing a broad range of feelings that individuals experience..." (Barsade \& Gibson, 2007, p. 37), and thus represents a more general well-being outcome. Affective experiences can be pleasant or unpleasant, following either highor low-activated states (Watson et al., 1988). Activated positive affect involves emotional reactions that are characterized by short but intense positive (e.g., enthusiasm, excitement) feelings. Emotional work engagement entails feeling emotionally connected to one's work role, including positive feelings regarding one's tasks and relationships (Rich et al., 2010). We decided to focus on emotional work engagement (e.g., as opposed to physical and cognitive engagement; Rich et al., 2010), because this facet of work engagement is most relevant to employee well-being. That is, it is a positive work-related state of mind (Schaufeli et al., 2002) that relates to positive affect (Demerouti et al., 2001; Rothbard, 2001).

Second, we investigate activated negative affect at work and emotional work fatigue as negative indicators of occupational well-being. Activated negative affect involves emotional reactions that are characterized by short but intense negative (e.g., frustrated, sad) feelings (Warr et al., 2014). Emotional work fatigue, which is a more specific indicator of occupational well-being, involves feeling tired and having reduced functional capacity at work (Frone \& Tidwell, 2015).

\section{Effects of Proactive Behavior on Occupational Well-Being}

As compared to most previous research that has shown that positive affect positively predicts proactive behavior (e.g., Bindl \& Parker, 2012; Fay \& Sonnentag, 2012; Fritz \& Sonnentag, 2009), we focus on the neglected topic of the affective and well-being consequences of proactive behavior. The short-term, lagged effects of proactive behavior on within-day changes in well-being outcomes, as investigated in this daily-diary study, have been conceptualized in the theoretical model by Cangiano and Parker (2016). This model specifies two pathways, one focusing on motivation and leading to positive well-being outcomes (e.g., activated positive affect), and the other focusing on resource-depletion resulting in negative well-being outcomes (e.g., job strain). The motivation pathway reflects proactive behavior that has been successful and likely fosters an employee's self-confidence and self-efficacy at work (Parker, 2000). The resource-depletion pathway, on the contrary, reflects proactivity as a source of employee stress (Bolino et al., 2010) that likely requires 
more resources and energy than available (Grant \& Ashford, 2008), thereby leading to negative well-being outcomes.

The opposing pathways proposed by Cangiano and Parker (2016) aim at uniting past research, which has not established uniform effects of proactivity on well-being outcomes. On the one hand, the positive association between proactive behavior and well-being outcomes has been found in several empirical studies. In addition to crosssectional evidence (e.g., Claes \& Van Loo, 2011; Ghitulescu, 2018; Greenglass \& Fiksenbaum, 2009; Wang \& Li, 2015), researchers have started to employ daily-diary (e.g., Starzyk et al., 2018; Weigelt et al., 2018) and experimental designs (e.g., Wolsink et al., 2019) to study relationships between proactivity and well-being. For example, Starzyk et al. (2018) conducted a daily-diary study, which found that problem-focused voice (i.e., a form of proactive behavior) during meetings was associated with higher positive affect at the end of the next working day. On the other hand, both crosssectional studies (e.g., Bolino \& Turnley, 2005) and daily-diary studies have demonstrated negative well-being consequences of proactive behavior as well. For example, Fay and Hüttges (2016) employed a daily-diary design spanning three days and found that daily proactive behavior was positively associated with daily cortisol output as an indicator of strain, but was not related to psychological measures of strain (i.e., fatigue). Recently, researchers have also started to use longitudinal research designs to study these relationships (e.g., Pingel et al., 2019; Strauss et al., 2017). For example, Pingel et al. (2019) used a three-wave longitudinal design ( $N=231$ participants) with surveys separated by 2 -week intervals to show that in the case of high external motivation, proactivity is positively related to both irritability and rumination.

Due to these mixed findings, we do not assume positive or negative main effects of proactivity on within-day changes in well-being outcomes. More specifically, because proactive behavior could result in either positive or negative well-being outcomes, the direction of the effects of proactive behavior on occupational well-being likely depends on moderators (Cangiano \& Parker, 2016). Therefore, we investigate whether past findings may be accounted for by a set of moderators that influence the direction and strength of the effects of proactive behavior. In contrast, previous research has focused on contextual moderators (e.g., punitive supervision or organizational support) of proactivity-well-being links. For example, considering both pathways, Cangiano et al. (2018) found evidence for an "energy-generating pathway" in a daily-diary study with professionals and managers by showing that engaging in proactive behavior on a daily basis can increase vigor due to a higher level of experienced competence at work. In addition, when perceived punitive supervision was high, proactive behavior was positively related to anxiety at the end of the workday, which in turn was negatively related to detachment from work at bedtime (i.e., a "resource-depletion pathway"). Further evidence for the importance of moderators comes from a study by Zacher et al. (2019). This study investigated the effects of changes in proactive behaviors over six months on changes in positive and negative mood, as well as emotional engagement and exhaustion over the following six months. Results of this study suggested that an increase in proactive behavior led to a decrease in positive mood and an increase in negative mood. In addition, a change in proactive behavior positively predicted a change in negative mood when perceived organizational support was low. Furthermore, an increase in personal initiative was indirectly related to a decrease in emotional engagement, and indirectly related to an increase in emotional exhaustion through a decrease in positive mood and an increase in negative mood, respectively. 


\section{The Moderating Effects of Organizational Tenure and Emotion Regulation Skills}

As argued here, the mixed findings regarding main effects of proactive behavior on wellbeing outcomes may be due to certain boundary conditions. Cangiano and Parker (2016) suggest that both individual (e.g., motivation) and contextual factors (e.g., feedback) may moderate the resource-generation and resource-depletion pathways. In their review of wise proactivity, Parker et al. (2019) aim to understand when proactivity is effective and when it is not. Parker et al. (2019) borrowed from the concept of wisdom (e.g., Baltes \& Staudinger, 2000) to establish wise proactivity, which is a meta-concept defined as "...enacting and implementing self-initiated and future-focused change that is contextually-sound, personally-sound, and other-focused..." (Parker \& Wang, 2015, p.71). As suggested by this definition, there are three elements that determine when proactivity is wise: First, the proactive behavior fits the context it is enacted in (i.e., it is contextually sound). Second, proactive behavior matches personal preferences and resources, while promoting personal growth (i.e., it is personally sound). Third, proactive behavior benefits others or serves their needs rather than, for example, worsening workload of already overburdened colleagues (i.e., it is other focused). Summing up, wise proactivity “...involves considering, in a balanced way, the task/strategic context, the social and relational context, and one's own self-regulation when generating and striving for proactive goals..." (Parker et al., 2019, p. 236).

The meta-concept of wise proactivity may help to understand under which conditions proactive behavior has positive or negative effects on occupational well-being. In the following, we explain how longer (vs. shorter) organizational tenure and higher (vs. lower) emotion regulation skills may help employees to adapt their behavior to the work and organizational environment and focus on proactive goals and address emotional events that may related to proactive behavior, respectively.

\section{Organizational Tenure}

Having higher relative organizational tenure (i.e., the duration that an employee has worked in an organization; Tesluk \& Jacobs, 1998), which is a quantitative aspect of work experience, could aid employees in engaging in proactive behavior that is both context-and person-centered. As a result, the enactment of proactive behavior is likely to better fit the context of the organization. For example, an employee may suggest a new method to address daily work tasks, which, despite its merits, may be turned down by colleagues if it does not fit the current focus or norms of the organization. Thus, even if the proactive behavior itself is highly beneficial to the organization, it may not be successful.

The reasoning behind the positive moderating effect of high organizational tenure on the relationship between proactive behavior and within-day changes in both positive and negative well-being outcomes is twofold: first, individuals with higher organizational tenure may have the experience to know their organization well while being experienced with regard to "how" proactivity may be best enacted. The latter could help them to better anticipate possible obstacles in regard to their proactive behavior by establishing a fit with the organizational context (i.e., it serves the definition of wise proactivity as being "contextually sound"). Moreover, higher tenured individuals may 
also be viewed by their coworkers as knowledgeable "veterans" of the organization whose attempts at proactivity are informed by a repertoire of experiences they have gained throughout their time as employees therein. Ultimately, when organizational tenure is high, individuals are better experienced in behaving proactively in a way that matches common norms and strategies present in an organization while also being perceived as acting proactively based on experience gained from their time in the organization, which likely results in positive well-being outcomes. For example, Bizzi (2017) states that when possessing high-levels of contextual information about the organization, job crafting (i.e., a specific type of proactive behavior) can be aligned with the organization's goals. Moreover, Dutton and Ashford (1993) found that individuals having more contextual knowledge can frame arising issues in a way that matches the context, for example, in terms of organizational strategy. The importance of tailoring issues to existing organizational goals, plans, or priorities, as well as knowledge about the organization's norms, protocols, and appropriate behaviors to successfully "sell an issue" has also been highlighted by other research (e.g., Ashford et al., 1998; Dutton et al., 2001; Howell \& Boies, 2004).

Second, organizational tenure helps employees better understand the values of their organization (Erdogan \& Bauer, 2005). This understanding, in turn, is likely to maximize the positive, while minimizing the negative, well-being outcomes of proactivity. That is, individuals with higher organizational tenure have a better understanding of which proactive behaviors will be accepted by other members of the organization, and those which go against the values and norms of the organization (i.e., serving the "otherfocused" aspect of wise proactivity). For example, in a study by Erdogan and Bauer (2005), being able to fit one's own (proactive) behavior to both the organization and the job resulted in positive career well-being and performance. This finding was explained by suggesting that the match of job knowledge and job requirements helps individuals more effectively deploy proactive behaviors by analyzing the situation and tailoring their problem-solving accordingly. In another study, Burris (2012) investigated the relationship between supportive voice and performance evaluations, finding that employees received higher performance ratings and endorsement of their ideas when planned policies and practices were upheld, in comparison to more challenging forms of voice aimed at changing organizational values. In a similar vein, Hirschfeld et al. (2011) found that proactivity oriented toward a team was perceived as more positive by observers compared to individually-oriented proactivity.

In contrast, having lower relative organizational tenure may decrease positive well-being outcomes while increasing negative well-being outcomes, as individuals may not have the experience to successfully enact proactivity, or may not be able to fully anticipate possible negative reactions to their proactive behavior. This, in turn, could result in proactivity that is not wise, and thus may not be successful within the organization. These threats to a person's selfconcept may result in decreased positive affect and increased negative affect, as manifested in feelings of depression, anger, or resentment (Vecchio, 2007). Moreover, as proactivity consumes resources, negative reactions may give the impression that previous resource investments are not translated into resource gains (Hobfoll, 1989). This potential resourceloss is likely to result in emotional work fatigue, as research has previously shown that negative events drain energetic resources, and thus relate to increase fatigue (Parrish et al., 2008; Zohar, 1999; Zohar et al., 2003). Simultaneously, work engagement would be reduced, as it is complementary to emotional work fatigue. 
In summary, because it provides the experience to engage in proactive behavior and may support the alignment of one's actions with the strategies, norms, and appropriate behaviors accepted in their organization, higher organizational tenure should buffer against any potentially negative effects of engaging in proactive behaviors (e.g., failing to adhere to organizational norms), and thus strengthen the positive effects of proactive behavior on within-day changes in positive well-being outcomes while reducing negative effects of proactive behavior on within-day changes in negative well-being outcomes. In contrast, those with low organizational tenure who do not have the benefit of experience may be more susceptible to the negative consequences of proactivity, which would ultimately strengthen the effects of proactive behavior on within-day changes in negative well-being outcomes while reducing the effects of proactive behavior on within-day changes in positive well-being outcomes.

Hypothesis 1: Organizational tenure moderates the effects of proactive behavior on within-day changes in (a) activated positive affect and (b) emotional work engagement, such that the effects are positive for employees with higher organizational tenure and negative for employees with lower organizational tenure.

Hypothesis 2: Organizational tenure moderates the effects of proactive behavior on within-day changes in (a) activated negative affect and (b) emotional work fatigue, such that the effects are negative for employees with higher organizational tenure and positive for employees with lower organizational tenure.

\section{Emotion Regulation Skills}

As proactive behavior is based on personal beliefs about what is important and aims at reaching a goal (Parker et al., 2010), it requires focus and avoidance of distractions (Parker et al., 2010). At the same time, due to the personal importance of proactive behavior, the process of behaving proactively is likely to be associated with strong emotional reactions, which may influence an individual's experiential, behavioral, or neurobiological states (J. J. Gross \& Thompson, 2007). Thus, emotion regulation is especially important when pursuing self-set goals that are associated with proactive behavior (Kanfer \& Kantrowitz, 2002).

In this study, we conceptualize emotion regulation skills as a trait-like (i.e., constant over the course of the study) variable that is defined in terms of "...how we try to influence which emotions we have, when we have them, and how we experience and express these emotions" (Gross, 1998; Gross \& Thompson, 2007, p. 497). We propose that higher emotion regulation skills help employees focus on their proactive goals by overcoming emotional events that may be related to their proactive behavior, such as setbacks. For example, emotion regulation skills may help employees to communicate their ideas clearly, confidently, and constructively (KishGephart et al., 2009). Additionally, emotion regulation skills could support employees in optimizing the timing of their proactive behavior (Grant, 2013). For example, instead of interrupting others during a meeting, a frustrated employee who can regulate this response may instead decide to remain silent while planning to deliberately speak up at another time, thereby constructively using their frustrations to identify problems and suggest solutions (Grant, 2013). Furthermore, employees with higher emotion regulation skills may reappraise the situation, using their frustration to reframe it as a challenge or opportunity, rather than a disappointment 
(Jordan et al., 2002). Employees with lower emotion regulation skills, however, may also express their anger, but with less control and constructive intent preventing the effective focus on identifying problems and solution, thus weakening the relationship between proactive behavior and positive well-being outcomes.

Ultimately, emotion regulation skills can help employees to manage and decrease negative emotions related to the process and outcomes of carrying out their behavior, but also help to maintain or increase positive affect associated with the process and outcomes of proactive behavior. The higher an employees' emotion regulation skills, the higher the likelihood that their proactive goals will continue to be pursued rather than abandoned (Parker et al., 2010). Moreover, higher emotion regulation skills may allow for the more effective management of negative affect associated with the proactivity process (Parker et al., 2010).

Hypothesis 3: Emotion regulation skills moderate the effects of proactive behavior on within-day changes in (a) activated positive affect and (b) emotional work engagement, such that the effects are positive for employees with higher emotion regulation skills and negative for employees with lower emotion regulation skills. Hypothesis 4: Emotion regulation skills moderate the effects of proactive behavior on within-day changes in (a) activated negative affect and (b) emotional work fatigue, such that the effects are negative for employees with higher emotion regulation skills and positive for employees with lower emotion regulation skills.

\section{Method}

\section{Participants and Procedure}

Data for this study came from 71 German employees between 21 and 63 years of age ( $M=40.01$ years, $S D=12.65$ years). Participants were recruited via both professional contacts (e.g., LinkedIn), as well as formal approaches via phone and email in different organizations. According to Highhouse and Gillespie (2009), the resulting sample is appropriate to accomplish theoretical generalizability (i.e., whether a hypothesized effect holds across populations) as the differences between participants can reflect the variability in the general population. Of the participants, $33(46.5 \%)$ were females and $38(33.5 \%)$ were males, with an average organizational tenure of 9.70 years $(\mathrm{SD}=$ 10.88). Participants mostly worked in the service sector (90\%), working an average of $44.15 \mathrm{~h}$ per week. Regarding their educational background, 11 had completed middle school (15.5\%), 13 completed high school (18.3\%), 45 held a university degree $(63.4 \%)$, and 2 indicated another educational background, such as a Ph.D. (2.8\%). There were 287 completed within-day (i.e., completed midday and late afternoon) surveys across all 71 participants. ${ }^{1}$ Based on the ratio between the completed surveys and the maximum number of completed within-day surveys (i.e., 710), the response rate was $40.42 \%$. Moreover, the minimum number of completed surveys was 2 while the maximum number was 20 .

\footnotetext{
${ }^{1}$ The total number of completed surveys was 828 ; however, only participants who completed both surveys on a given day were included in the final sample considered in our analyses.
} 
The present study used a daily-diary design to investigate relationships between proactivity during the first half of the workday on within-day changes in well-being outcomes during the second half of the workday (i.e., controlling for well-being outcomes during the first half of the workday), as well as organizational tenure and emotion regulation skills as moderators of these relationships. Daily-diary designs help one to understand short-term, intra-individual changes (S. Gross et al., 2013), while providing sufficient ecological validity (Fisher \& To, 2012). The questionnaires, which were sent out on weekdays only, were programmed, distributed, and completed through "formr," an R-based online tool for creating automated study designs (Arslan et al., 2018). Participants were instructed to respond to the surveys only on workdays and questions were framed around the workday. After participants agreed to take part in the study and provided their email address, they were automatically sent a link to a baseline questionnaire including measurements of the within-day variables, as well as the moderators, one week before the actual start of the study. As their answers were saved without reference to the entered email address but by using a number-letter combination as an alias, anonymity was guaranteed.

After completing the baseline questionnaire, participants were automatically sent the link to the first of two daily assessments the first Monday after completing the baseline questionnaire. The two within-day questionnaires were distributed at 11 a.m. and 4 p.m. from Monday to Friday during the following two weeks. The links to the questionnaires could be opened up to $90 \mathrm{~min}$ after receiving the link and had to be completed within 90 min after opening the link. The questionnaires always included the same items, taking between two and five minutes to complete. After two weeks, participants were thanked for their participation and given the possibility to receive a summary of the results upon request.

\section{Measures}

All originally English questionnaires were translated to German and back-translated to English for comparison following the advice of Brislin (1970). Consistent with recent advancements (see Gabriel et al., 2019; Geldhof et al., 2014), we report reliability estimates for within-day survey measures at both the between- and within-person level of analysis.

Proactive Behavior Proactive behavior was measured twice a day (i.e., midday and late afternoon) using the 7-item personal initiative scale from Frese et al. (1997), which was adapted to the day-level. Personal initiative is a broad form of proactive behavior that encompasses various specific behaviors. Examples of personal initiative include initiating change to improve working conditions (i.e., taking charge) and proactively seeking feedback on how the desired change is proceeding. An example item was "During the last half of my working day, I actively approached problems." All items were scored on a 7-point Likert scale ranging from $1=$ strongly disagree to $7=$ strongly agree. At the between-person level, the reliability of the midday measure was $\alpha=.94$, and the reliability of the late afternoon measure was $\alpha=.98$. At the withinperson level, the reliability of the midday measure was $\alpha=.84$, and the reliability of the late afternoon measure was $\alpha=.87$. 
Activated Positive and Negative Affect Activated positive and negative affect were assessed twice a day (i.e., midday and late afternoon) using a shortened version of the IWP-Multi-Affect Indicator by Warr et al. (2014). The measures consisted of 8 (enthusiastic, calm, relaxed, excited for activated positive affect; tense, hopeless, depressed, anxious for activated negative affect) of the 16 original items. Moreover, we adapted the items by instructing participants to record how often they felt each of the emotions during the last half of their working day. Activated positive and negative affect were scored on 7-point scales ranging from "Never $=0 \%$ of the time" to "Always $=100 \%$ of the time."

At the between-person level, the reliability of both the midday and late afternoon measure of activated positive affect was $\alpha=.95$. At the within-person level, the reliability of the midday measure for activated positive affect was $\alpha=.75$, and the reliability of the late afternoon measure was $\alpha=.72$.

At the between-person level, the reliability of both the midday and late afternoon measure of activated negative affect was $\alpha=.76$. At the within-person level, the reliability of the midday measure for activated negative affect was $\alpha=.52$, and the reliability of the late afternoon measure was $\alpha=.56$.

Emotional Work Engagement Emotional work engagement was assessed with items developed by Rich et al. (2010). Based on the highest factor loadings, the original 6item scale was shortened to 4 items and adapted to the day level. An example item was "During the last half of my working day, I was enthusiastic in my job." All items were scored on a 7-point Likert scale ranging from $1=$ strongly disagree to $7=$ strongly agree. At the between-person level, the reliability of both the midday and late afternoon measure was $\alpha=.94$. At the within-person level, the reliability of the midday measure for positive activated affect was $\alpha=.82$, and the reliability of the late afternoon measure was $\alpha=.78$.

Emotional Work Fatigue Emotional work fatigue was assessed using items from Frone and Tidwell (2015). Based on the highest factor loadings, the original 6-item scale was shortened to 3 items and adapted to the day level. An example item was "During the last half of my working day, I felt emotionally exhausted." All items were scored on a 7-point Likert scale ranging from $1=$ strongly disagree to $7=$ strongly agree. At the between-person level, the reliability of both the midday and late afternoon measure was $\alpha=.98$. At the withinperson level, the reliability of the midday measure for positive activated affect was $\alpha=.87$, and the reliability of the late afternoon measure was $\alpha=.85$.

Organizational Tenure In accordance with Tesluk and Jacobs (1998), organizational tenure was operationalized by asking participants to indicate, in years, how long they have been working for their current organization. This measure was collected in the baseline questionnaire, and thus was assessed once at the beginning of the study.

In the context of this study, it is important to distinguish organizational tenure from job tenure or job experience. Whereas organizational tenure describes the time spent at an organization, job tenure/experience describes the time spent in a specific job (Tesluk \& Jacobs, 1998). In the present study, job-related knowledge will not be investigated, as proactive behavior aims at changing the status quo, which often differs between organizations. Moreover, only knowledge about the contextual (work) environment 
was identified as a prerequisite for engaging in wise proactivity by Parker et al. (2019). Nevertheless, job tenure may contribute to findings regarding organizational tenure. Yet, due to the overlap of these concepts (e.g., regarding their relationship to time), effects are difficult to separate.

Emotion Regulation Skills Regulation of one's own emotions was assessed with four items collected during the baseline questionnaire using a subdimension of the selfreport emotional intelligence test (SREIT) developed by Law et al. (2004). An example item is "I have good control over my own emotions." Answers were scored on a 7point Likert scale ranging from $1=$ strongly disagree to $7=$ strongly agree. The between-person reliability was $\alpha=.89$.

Age Chronological age was operationalized as the time passed since birth. Participants were asked to indicate their age in years in the baseline questionnaire.

\section{Statistical Analyses}

Given the measures of proactive behavior, activated positive and negative affect, and emotional work engagement and work fatigue were nested within-person, we used a mixed-effects modelling strategy to test our hypotheses. All models were specified using the "Ime4" package (Bates et al., 2014) for the R statistical computing environment. Beyond accounting for dependencies due to nesting of observations within-person, the additional advantage of such models is that they allowed us to model effects of proactive behavior on within-day changes in activated positive and negative affect, emotional work engagement, and emotional work fatigue outcomes, and cross-level interactions between proactivity, tenure, and emotion regulation skills on such outcomes.

When analyzing time-lagged effects, it is important to control for "baseline" levels of modeled outcomes to predict changes across the time-lag (i.e., to employ a lagged endogenous change model; Aickin, 2009; Finkel, 2008). Thus, we control for midday well-being outcomes to represent changes in well-being across the workday. Well-being often fluctuates over relatively short time-periods (e.g., within-day). This makes lagged within-person designs such as we employ here an appropriate approach for understanding the well-being outcomes of proactive behavior (Xanthopoulou et al., 2012), as they can also account for the time-lag between proactive behavior and well-being outcomes (i.e., to investigate effects of proactive behavior during the first half of the workday on within-day changes in positive or negative well-being outcomes at the end of the workday).

To allow for modelling lagged endogenous levels of our outcome variables, we used a within-day data structure in our analyses. Specifically, data were structured such that late afternoon levels of each outcome were modelled controlling for midday levels. That is, we model midday-measures of proactivity as a predictor of late afternoon wellbeing outcomes, while controlling for midday-measures of well-being. Beyond timelagged effects of outcome variables and midday levels of proactive behavior, our models additionally included baseline measures of organizational tenure and emotion regulation skills as well as chronological age (i.e., to rule out the effects of organizational tenure being purely a function of age). All predictors were entered into these models as fixed effects. 
All momentary measures (i.e., predictors and lagged endogenous outcomes) were person-mean centered to isolate and model within-person components (i.e., fluctuations from the person-mean level) from stable, between-person components (i.e., the average person level) of these variables (see Bolger \& Laurenceau, 2013, pp. 77-78). As we model late afternoon levels while controlling for midday levels of our outcome variables, resulting parameters for momentary measures can be interpreted in terms of average within-day changes in within-person levels from midday to late afternoon in the outcome variables across the days of the study. Additionally, chronological age, organizational tenure, and emotion regulation skills were grand mean centered. Finally, we offer estimates of within-person variance explained by our models (pseudo- $R^{2}$ estimates). Specifically, we report such estimates using formulae from Raudenbush and Bryk (2002) and Snijders and Bosker (2012).

To support these models, we conducted a multilevel confirmatory factor analysis of all momentary measures. We specified a five-factor model that differentiated all five momentary measures and compared the fit of this model to a one-factor model that combined all five measures into a single latent variable. The five-factor model fit the data well $\left(\chi^{2}=548.79, \mathrm{df}=218, p<.001 ; \mathrm{CFI}=.92, \mathrm{TLI}=.90, \mathrm{RMSEA}=.05\right.$, $\left.\mathrm{SRMR}_{\text {within }}=.04, \mathrm{SRMR}_{\text {between }}=.09\right)$, and demonstrated superior fit to the data when compared to the one-factor model $\left(\Delta \chi^{2}=1990.40, \mathrm{df}=20, \mathrm{p}<.001\right)$.

\section{Results}

Table 1 reports between- and within-person correlations among our study variables. Initially, we specified a series of null (i.e., intercept-only) models, and computed intraclass correlations $\left(\mathrm{ICC}_{1}\right)$ to ascertain the amount of variance attributable to within-person variation in our outcome variables. $\mathrm{ICC}_{1}$ estimates ranged from .74 (fatigue) to .48 (negative affect) suggesting between $(1.00-.783=.217) 21.70 \%$ and $(1.00-.483=.517) 51.70 \%$ of the variability in late afternoon levels of these outcomes occurs within-person. Table 2 summarizes the mixed effects models specified to test our four study hypotheses.

\section{Main Effects}

Regarding the main effects of proactive behavior on well-being outcomes, we did not find significant effects. More specifically, proactive behavior was unrelated to withinday changes in activated negative affect $\left(B=-0.06, S E_{B}=0.05, p=.23\right)$, activated positive affect $\left(B=0.03, S E_{B}=0.06, p=.67\right)$, emotional work engagement $(B=0.07$, $\left.S E_{B}=0.06, p=.22\right)$ and emotional work fatigue $\left(B=0.04, S E_{B}=0.05, p=.41\right)$. Given that we hypothesize conditional (i.e., moderated) effects of proactive behavior on wellbeing outcomes, and that higher-order interaction terms are present in these models, the results reported here regarding main effects should be interpreted with some caution.

\section{Moderation Effects}

In summary of our hypothesis tests, we only noted support for Hypothesis $4 \mathrm{~b}$. Specifically, we posited that emotion regulation skills would interact with day-level 


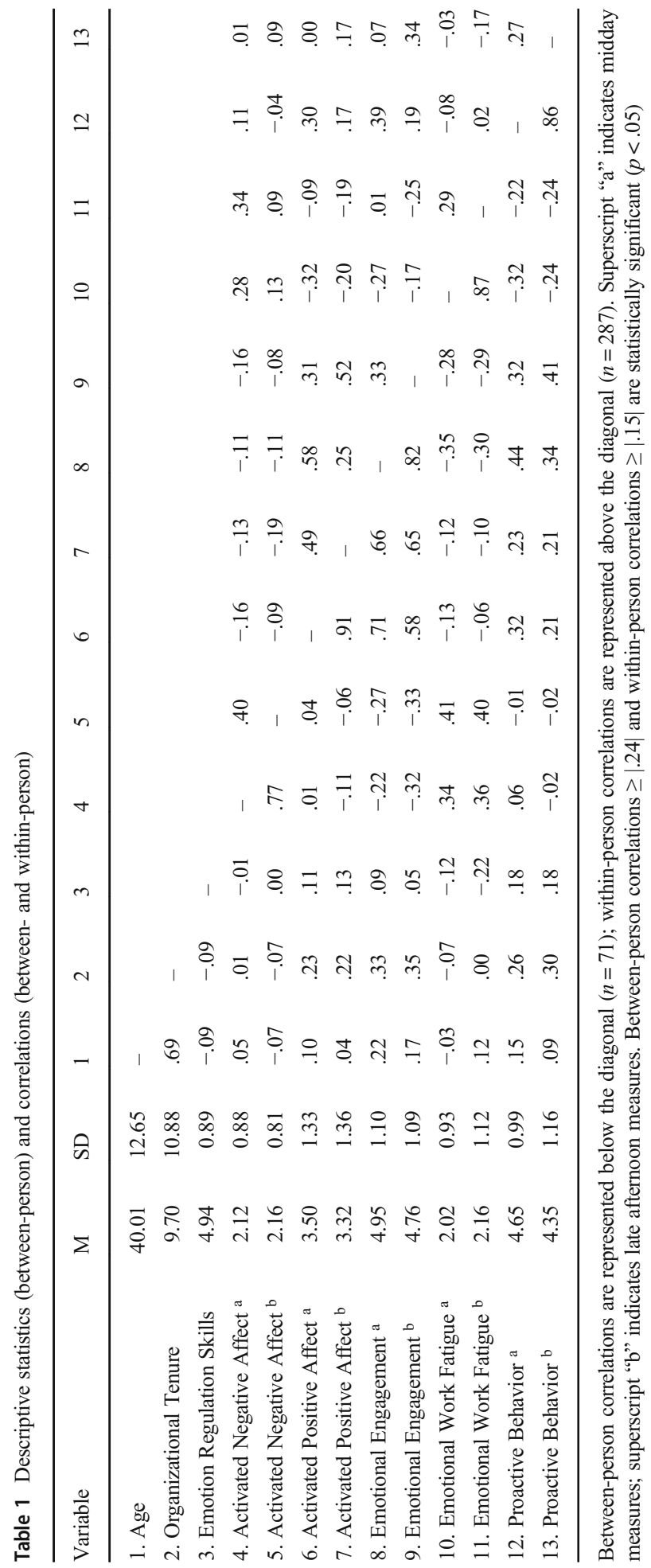




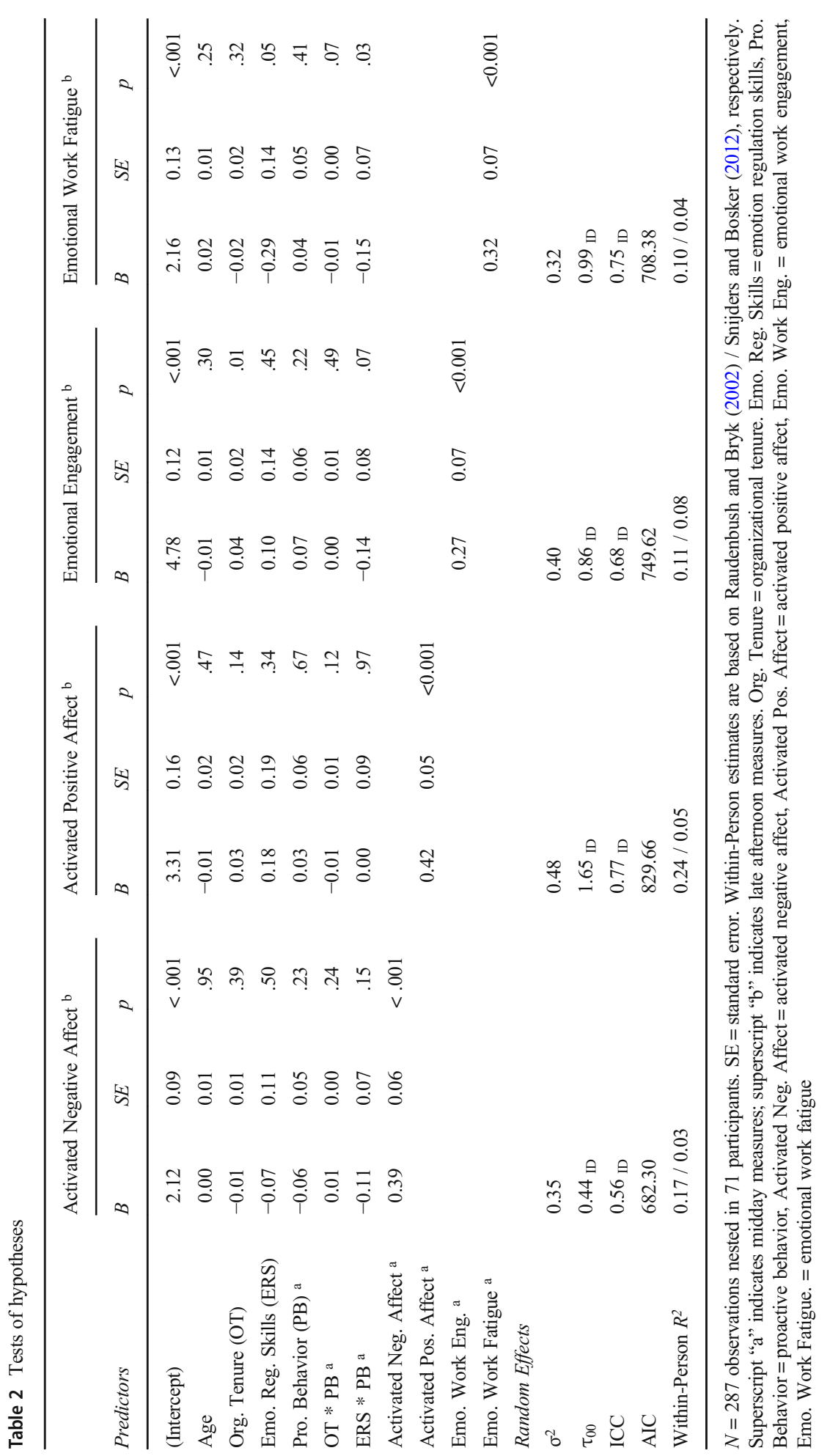


proactive behavior to predict changes in day-level emotional work fatigue ( $B=-0.15$, $S E_{B}=0.07, p=.028$ ). Follow-up simple slopes tests partially confirmed the form of our hypothesized relationship (see Table 4). Specifically, the effects of proactive behavior on within-day changes in emotional work fatigue were positive for employees with moderately low ( -1 S.D., $B=0.17, S E_{B}=0.08, p=.034$ ) and low emotion regulation skills ( -2 S.D., $B=0.29, S E_{B}=0.13, p=.023$ ). However, for employees with average or higher emotion regulation skills we observed no effects of proactive behavior on within-day changes in emotional work fatigue. Figure 2 graphically depicts this relationship.

\section{Additional Analyses}

We additionally investigated potential "reverse" effects of these four outcome variables on within-day changes in proactive behavior via models in which late afternoon proactive behavior was treated as an outcome variable while controlling for midday measures of proactive behavior (see Table 3). The reasoning behind this additional analysis was that previous research has mostly focused on the effects of affect (i.e., an indicator of occupational well-being) on proactive behavior, concluding that positive affect stimulates proactive behavior, whereas negative affect decreases it (see Cangiano et al., 2017; for a review). To acknowledge and empirically examine this previous line of research, we have additionally examined the reverse relationship. In summary, we observed two statistically significant interactions between organizational tenure and activated positive $\left(B=0.02, S E_{B}=0.01, p=.021\right)$ and activated negative affect $(B=$ $\left.0.02, S E_{B}=0.01, p=.025\right)$, predicting within-day changes in proactive behavior. The interpretation of both interactions is similar: follow-up simple slopes tests (Table 4) show that for employees with lower organizational tenure, the experience of either activated positive ( -2 S.D., $B=-0.41, S E_{B}=0.16, p=.014$ ) or activated negative affect

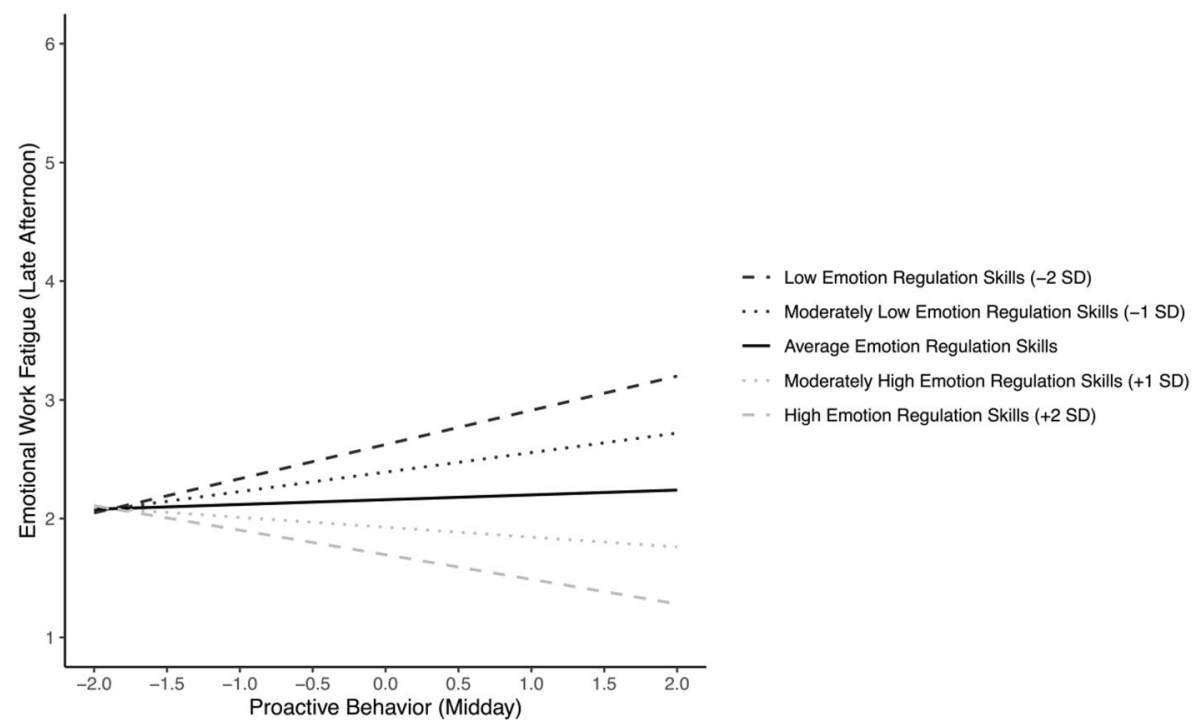

Fig. 2 Moderating Effect of Emotion Regulation Skills on the Relationship Between Proactive Behavior (Midday) and Emotional Work Fatigue (Late Afternoon) 
Table 3 Additional analysis

\begin{tabular}{|c|c|c|c|}
\hline \multirow[b]{2}{*}{ Predictors } & \multicolumn{3}{|c|}{ Proactive Behavior ${ }^{b}$} \\
\hline & $B$ & $S E$ & $p$ \\
\hline (Intercept) & 4.33 & 0.13 & $<.001$ \\
\hline Age & -0.02 & 0.01 & .10 \\
\hline Pro. Behavior $(\mathrm{PB})^{a}$ & 0.31 & 0.07 & $<.001$ \\
\hline Org. Tenure (OT) & 0.05 & 0.02 & .00 \\
\hline Emo. Reg. Skills (ERS) & 0.20 & 0.15 & .18 \\
\hline Activated Pos. Affect a & -0.06 & 0.07 & .40 \\
\hline Activated Neg. Affect a & -0.02 & 0.09 & .85 \\
\hline Emo. Work Eng. a & -0.05 & 0.11 & .61 \\
\hline Emo. Work Fatigue a & -0.08 & 0.11 & .47 \\
\hline OT $*$ Activated Pos. Affect ${ }^{a}$ & 0.02 & 0.01 & .02 \\
\hline OT $*$ Activated Neg. Affect a & 0.02 & 0.01 & .03 \\
\hline OT $*$ Emo. Work Eng. ${ }^{\text {a }}$ & -0.02 & 0.01 & .10 \\
\hline OT $*$ Emo. Work Fatigue ${ }^{a}$ & -0.01 & 0.01 & .29 \\
\hline Activated Pos. Affect a $*$ ERS & 0.06 & 0.10 & .53 \\
\hline Activated Neg. Affect a $*$ ERS & 0.20 & 0.10 & .05 \\
\hline Emo. Work Eng. a $*$ ERS & 0.00 & 0.14 & .98 \\
\hline Emo. Work Fatigue a $*$ ERS & 0.02 & 0.17 & .91 \\
\hline \multicolumn{4}{|l|}{ Random Effects } \\
\hline$\sigma^{2}$ & 0.59 & & \\
\hline$\tau_{00 \mathrm{ID}}$ & 0.95 & & \\
\hline $\mathrm{ICC}_{\mathrm{ID}}$ & 0.62 & & \\
\hline AIC & 888.61 & & \\
\hline Within-Person $R^{2}$ & $0.08 / 0.09$ & & \\
\hline
\end{tabular}

$N=287$ observations nested in 71 participants. $\mathrm{SE}=$ standard error. Within-Person estimates are based on Raudenbush and Bryk (2002) / Snijders and Bosker (2012), respectively. Superscript "a" indicates midday measures; superscript " $b$ " indicates late afternoon measures. Org. Tenure = organizational tenure. Emo. Reg. Skills $=$ emotion regulation skills, Pro. Behavior $=$ proactive behavior, Activated Neg. Affect $=$ activated negative affect, Activated Pos. Affect = activated positive affect, Emo. Work Eng. = emotional work engagement, Emo. Work Fatigue. = emotional work fatigue

$\left(-2\right.$ S.D., $\left.B=-.40, S E_{B}=0.19, p=.036\right)$ at work was associated with lower subsequent proactive behavior. Figures 3 and 4 depict these relationships for activated positive and negative affect, respectively. In our discussion, below, we speculate as to why such relationships were observed.

\section{Sensitivity Analysis}

We also consider two sensitivity analyses to examine the robustness of our conclusions. First, we include the results of models without lagged effects in our online appendix. Compared to the models with lagged effects, we observed a significant positive relationship between proactive behavior and activated positive affect $\left(B=0.18, S E_{B}=\right.$ 
Table 4 Simple slope analysis for the interaction between proactive behavior (midday) and emotion regulation skills with emotional work fatigue (late afternoon) as outcome

\begin{tabular}{|c|c|c|c|c|c|}
\hline Simple Slope & $B$ & $S E$ & $t$ & $d f$ & $p$ \\
\hline \multicolumn{6}{|l|}{ Model 1} \\
\hline Emotion regulation skills ( $-2 \mathrm{SD})$ & 0.29 & 0.13 & 2.29 & 212 & .023 \\
\hline Emotion regulation skills ( $-1 \mathrm{SD})$ & 0.17 & 0.08 & 2.14 & 212 & .034 \\
\hline Emotion regulation skills (0 SD) & 0.04 & 0.05 & 0.83 & 212 & .407 \\
\hline Emotion regulation skills $(+1 \mathrm{SD})$ & -0.08 & 0.07 & -1.16 & 212 & .250 \\
\hline Emotion regulation skills $(+2 \mathrm{SD})$ & -0.21 & 0.12 & -1.73 & 212 & .085 \\
\hline \multicolumn{6}{|l|}{ Model 2} \\
\hline Organizational Tenure ( $-2 \mathrm{SD})$ & -0.41 & 0.16 & -2.47 & 203 & .014 \\
\hline Organizational Tenure (-1 SD) & -0.23 & 0.10 & -2.27 & 203 & .025 \\
\hline Organizational Tenure (0 SD) & -0.06 & 0.07 & -0.83 & 203 & .405 \\
\hline Organizational Tenure (+1 SD) & 0.11 & 0.11 & 1.05 & 203 & .295 \\
\hline Organizational Tenure (+2 SD) & 0.28 & 0.17 & 1.69 & 203 & .093 \\
\hline \multicolumn{6}{|l|}{ Model 3} \\
\hline Organizational Tenure (-2 SD) & -0.40 & 0.19 & -2.11 & 203 & .036 \\
\hline Organizational Tenure ( $-1 \mathrm{SD})$ & -0.21 & 0.12 & -1.73 & 203 & .085 \\
\hline Organizational Tenure (0 SD) & -0.02 & 0.09 & -0.19 & 203 & .849 \\
\hline Organizational Tenure (+1 SD) & 0.17 & 0.12 & 1.41 & 203 & .159 \\
\hline Organizational Tenure (+2 SD) & 0.37 & 0.19 & 1.89 & 203 & .060 \\
\hline
\end{tabular}

Model 1 =proactive behavior (midday) and emotion regulation skills with emotional work fatigue (late afternoon) as outcome, Model 2 organizational tenure and activated positive affect (midday) with proactive behavior (late afternoon) as outcome, Model 3 = organizational tenure and activated negative affect (midday) with proactive behavior (late afternoon) as outcome, $\mathrm{SE}=$ standard error, Org. Tenure = organizational tenure. Emo. Regulation $=$ emotion regulation skills, Pro. Behavior $=$ proactive behavior, Activated Neg. Affect $=$ activated negative affect, Activated Pos. Affect $=$ activated positive affect, Emo. Work Fatigue. $=$ emotional work fatigue

$0.07, p<.01)$ and emotional engagement $\left(B=0.04, S E_{B}=0.02, p<.01\right)$. It is important to acknowledge that these sensitivity models are not about within-day change, but rather late afternoon levels, and that comparisons should be interpreted with caution. Second, given that both chronological age and organizational tenure are temporally defined variables, we wanted to check the sensitivity of our conclusions to the inclusion of chronological age as a covariate. Thus, in addition to our specified models, we calculated other models without age as a control variable. Therein, the parameter estimates, and the substantive conclusions drawn were the same if age was omitted. Complete results for both models can be seen in our online appendix: https:/osf.io/ jyhsq/

\section{Discussion}

In this study, we investigated the effects of proactive behavior on within-day changes in four distinct well-being outcomes with two daily assessments, as employee well-being 


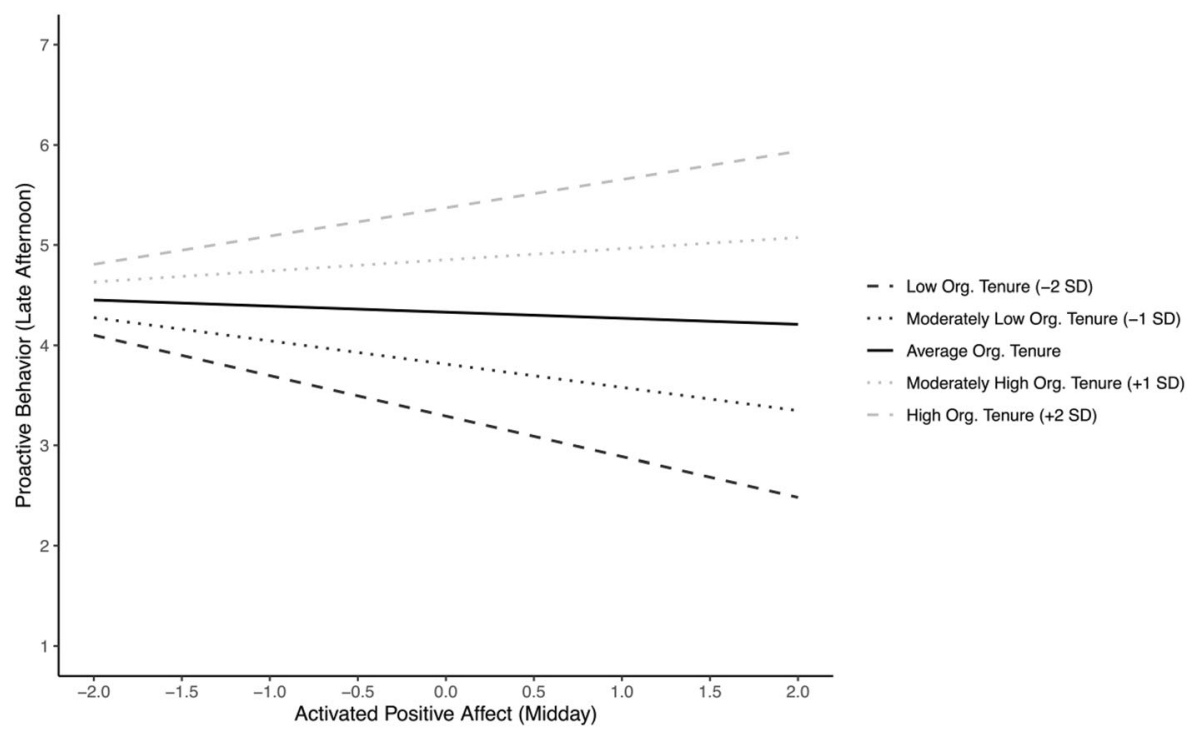

Fig. 3 Moderating Effect of Organizational Tenure on the Relationship Between Activated Positive Affect (Midday) and Proactive Behavior (Late Afternoon)

may vary both within and across workdays. Based on a theoretical model by Cangiano and Parker (2016), we focused on moderators of the effects of proactive behavior on within-day changes in activated positive affect and emotional work engagement, as well as within-day changes in activated negative affect and emotional work fatigue. Although not the focus of this research, we did not find evidence for main effects of proactive behavior on within-day changes in well-being outcomes. However, research

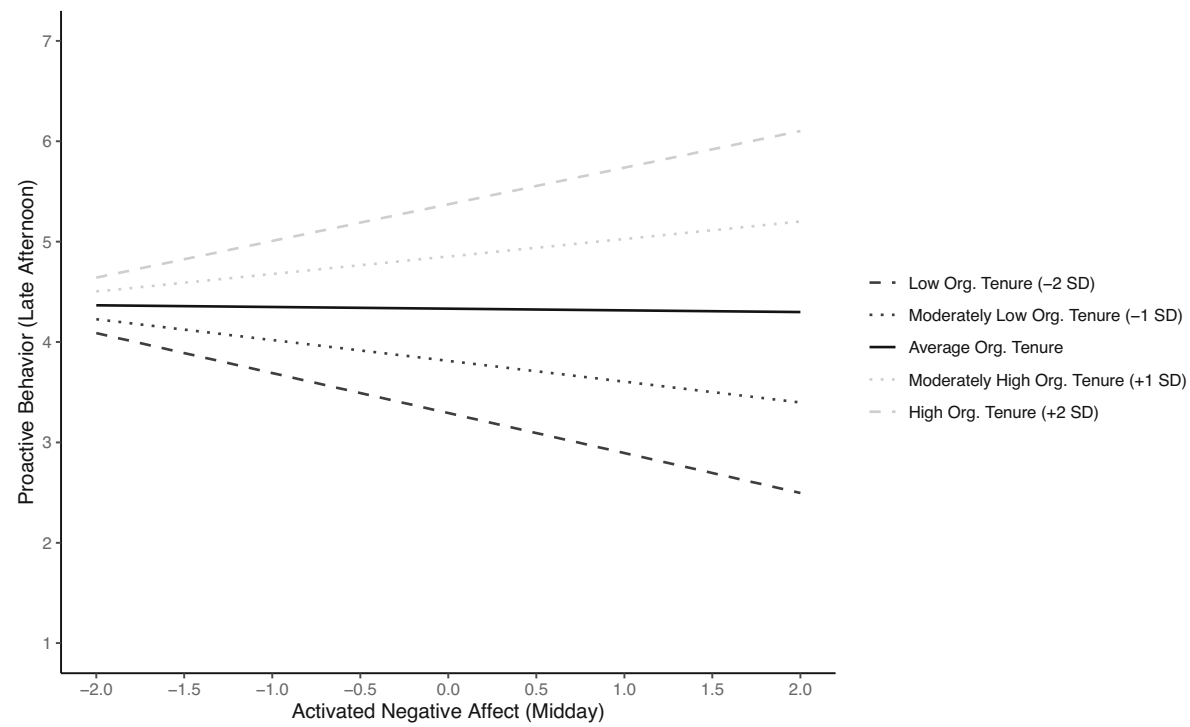

Fig. 4 Moderating Effect of Organizational Tenure on the Relationship Between Activated Negative Affect (Midday) and Proactive Behavior (Late Afternoon) 
has not generally hypothesized such main effects directly and support for the presence and strength of such relationships between proactive behavior and well-being is mixed and qualified by the presence of moderators (see Cangiano et al., 2017, for a review).

Based on the meta-concept of wise proactivity that aims to identify those factors that enhance favorable and minimize unfavorable outcomes of proactive behavior (Parker \& Liao, 2016; Parker et al., 2019), we included organizational tenure and emotion regulation skills as moderators of the relationship between proactive behavior and within-day changes in well-being outcomes. Contrary to our expectations, we did not find support for the hypothesized moderation effects of organizational tenure. One reason for this may be that past research has employed different designs and analytic approaches when investigating directional effects of proactive behavior on well-being and its moderators. Although we examined lagged effects and controlled for withinperson effects of our dependent variables by including midday measures when examining late afternoon measures, previous studies investigating organizational tenure as a moderator of proactivity effects are mostly between-person survey studies (Ashford \& Cummings, 1985; Gerhardt et al., 2009). This conditional relationship may, however, be different at the within-person level (Parker et al., 2019).

Another explanation for the non-significant moderation effects of organizational tenure may be that although organizational tenure, or knowledge about an organization's traditions and dynamics, has been identified as an important theoretical factor consistent with the notion of wise proactivity (Parker et al., 2019), there may be other, potentially more influential variables that could aid employees in assessing whether their proactive behavior might fit the organizational context or be well-received by others. For example, although individuals with higher organizational tenure tend to know more about the organization and its transitions, they may not be committed to the organization or may not share organizational values. In this case, proactive behavior would not be aligned with current organizational goals and values, and thus would not be "wise." An example are mergers or acquisitions, where two different organizations with unique cultures need to interact to form a new corporate culture. This often requires time and effort from both employees and organizations (Seo \& Hill, 2005).

With regard to emotion regulation skills, we found support for the assumption that emotion regulation skills moderate the effects of proactive behavior on within-day changes in emotional work fatigue, such that the effects were positive for employees with lower emotion regulation skills. Our findings can be explained by low emotion regulation skills hindering coping with possible negative effects of proactive behavior (Parker et al., 2019), which ultimately strengthens the effects of proactive behavior on negative well-being outcomes. In contrast, we did not find an equivalent effect on activated negative affect. A reason for this may be that activated negative affect is a general well-being indicator, whereas emotional work fatigue is an occupational wellbeing indicator. As stated by Sonnentag (2015), scholars often emphasize hedonic wellbeing (i.e., affective and psychosomatic well-being), while organizational research adds eudaimonic aspects of well-being (e.g., when addressing meaning at work or growth). Most importantly, Sonnentag (2015) notes that the well-being of employees is influenced by work experiences. As we asked participants about their proactive behavior at work, its well-being outcomes are likely to be work-related as well. Thus, as emotional work fatigue measures fatigue at work specifically, it may be the context of the study that influences participants' ratings of well-being outcomes following their proactive 
behavior. The distinction between the two well-being outcomes can also be seen in Table 1, where late afternoon measures of activated negative affect and emotional work fatigue are not significantly correlated with one another $\left(r_{x y}=0.09, p>.05\right)$.

We did not find support for the hypothesis that the effects of proactive behavior on within-day changes in activated positive affect and emotional work engagement are stronger for employees with high (vs.) low emotion regulation skills. One reason for the lack of support for the moderating role of emotion regulation skills for positive wellbeing outcomes may be that negative outcomes occur unconditionally when proactive behavior is well-received. In other words, emotion-regulation abilities may be irrelevant when proactive behavior has positive consequences but matter more when negative well-being effects need to be buffered. Such a "feedback" mechanism should be considered for future studies.

Our supplementary analyses, which were not the primary focus of the study, centered on (assumed) reverse effects of occupational well-being on within-day changes in proactive behavior. The analyses revealed two interactions between organizational tenure and activated positive and negative affect in predicting within-day changes in proactive behavior. More specifically, for employees with lower organizational tenure, the experience of either activated positive or negative affect at work was associated with lower subsequent proactive behavior. From these results, it seems that organizational tenure facilitates the translation of affective experience at work into proactive behavior. That is, high arousal affective experiences that occur earlier in the day, regardless of their positive or negative valence, facilitate the enactment of proactive behavior later in the day, but only for individuals with higher organizational tenure.

The importance of both positive and negative high arousal affective experiences has been suggested by past research (Den Hartog \& Belschak, 2007; Fay \& Sonnentag, 2002; Sonnentag \& Starzyk, 2015). For example, in a four-wave longitudinal study by Fay and Sonnentag (2002), the authors showed that not only activated positive affect, but also stress (i.e., activated negative affect) can lead to greater proactive behavior. The reasoning that organizational tenure helps people channel high arousal emotions into proactive behavior is supported by the strength and vulnerability integration model (i.e., the SAVI model; Charles, 2010). The SAVI model aims to explain age-related strengths and vulnerabilities in emotion-regulation. According to the model, chronological age can be seen as a proxy for experience (Schwall, 2012), such that experience (or tenure) increases with age (Tesluk \& Jacobs, 1998). Based on this perspective, older individuals, and consequently those with higher organizational tenure, are more likely to possess the knowledge to effectively regulate their emotions. Additional support for effective emotion-regulation with tenure (or age as a proxy) comes from the emotional capital perspective (Andrew, 2015; Cottingham, 2016), in which "emotional capital" is viewed as a resource that can be strengthened through learning from successful emotion regulation over time. Considering organizational tenure and proactive behavior, higher organizational tenure, which also increases with age, is likely to provide the knowledge needed to effectively regulate high-arousal emotions into proactive behavior.

\section{Theoretical and Practical Implications}

Research has shown that both positive and negative well-being outcomes may result from proactive behavior. Yet, to accurately capture the well-being outcomes of 
proactive behavior, both positive and negative well-being indicators need to be taken into account when modelling these relationships. Thus, in contrast to previous research, the present study focused on both positive and negative well-being outcomes of proactive behavior as described in the theoretical model by Cangiano and Parker (2016). First, we found that since the main effects of proactive behavior on withinday changes in the assessed well-being outcomes were non-significant, some of these relationships may depend on moderators, and especially emotion regulation skills, as found in this study.

Second, we investigated variables consistent with the meta-concept of wise proactivity (Parker et al., 2019). Specifically, our results show support for (relatively lower) emotion regulation skills strengthening the negative relationship between proactive behavior and within-day changes in negative well-being outcomes. Furthermore, we found that organizational tenure can help people to channel high arousal emotions into proactive behavior. Our results are thus a first step in confirming the influences currently being theoretically considered as aspects of the meta-concept of wise proactivity (e.g., considering the context; Parker et al., 2019). Using this knowledge, current theoretical models should consider different moderator variables related to the concept of wise proactivity to understand what determines the wellbeing consequences of proactive behavior.

Third, by employing a daily-diary design, our study allows us to focus on fluctuations in well-being within shorter periods of time (i.e., within days; Sonnentag, 2015). An example of such changes is the organizational socialization process, wherein an employee's well-being can change, with a notable decline in positive and an increase in negative states during the first few months after entering an organization (Dunford et al., 2012; Kammeyer-Mueller et al., 2013). In a meta-analysis, Shockley et al. (2012) found that a substantial amount - about $40 \%$ of the total variance in positive, workrelated affect and about $53 \%$ of the total variance in activated negative, work-related affect - is attributable to fluctuations within-persons. Thus, when investigating wellbeing, theory should consider short-term effects to capture the dynamics intertwined with well-being at work, as done in the present study.

From a practical perspective, researchers and organizations alike have focused on the beneficial effects of proactive behavior, particularly on job performance (Tornau \& Frese, 2013). In contrast, empirical studies on well-being outcomes following proactive behavior are rare (Cangiano et al., 2017). Our results lend first support for emotion regulation skills as a relevant factor to wise proactivity and well-being. Based on these findings, organizations may decide to offer employee trainings to increase emotion regulation skills. Thereby, employees may be less likely to experience work fatigue after engaging in proactive behavior, as the effect of proactive behavior on emotional work fatigue was only positive for employees with low (vs. high) emotion regulation skills in our study. The findings from our exploratory analysis further suggest that especially for employees with lower (vs. higher) organizational tenure, both activated positive and negative affect were negatively associated with proactive behavior, which may encourage organizations to build a business case for hiring experienced (i.e., older) workers.

\section{Limitations and Future Research}

This study has some limitations. First, all variables were assessed using self-report questionnaires. Even when modelling a time-lag between the predictor and outcome 
measurement, as done in this study, common-measurement bias cannot be ruled out completely (Podsakoff et al., 2003). Future research should, for example, also assess more objective indicators from co-workers or team leaders to ensure a maximum of objectivity (see Strauss et al., 2017 for an example). Moreover, the reliabilities for the within-person measures of negative affect were somewhat low. Future studies therefore may consider using different measures of affect (e.g., longer forms of the IWP-MultiAffect Indicator; Warr et al. (2014).

Second, the response rates for the study were rather low. Reasons could be the timeconsuming baseline questionnaire (approximately $20 \mathrm{~min}$.), which might have raised false expectations in regard to the two daily questionnaires (approximately $5 \mathrm{~min}$. each). Moreover, completing two questionnaires a day might be exhausting and hard to fit into one's working day. Our data also showed that response rates were especially low during the second week of the study, hinting that the repeating two daily questionnaires could have been too monotonous, which ultimately reduced motivation. Future studies might be well-advised to offer rewards for participation, and to recruit complete organizations wherein employees can motivate each other to participate.

A final limitation might be the selection of participants. As participation was voluntary and not rewarded, it could be that participants were mostly proactive, which would challenge the generalizability of these results. On a related note, the average work hours in the sample were $44 \mathrm{~h}$ per week. As the regular full-time working hours German employees have (and per contract have to obey to) are $40 \mathrm{~h}$ a week, this indicates that participants, on average, worked 4 h overtime every week. Despite this, the investigated hypotheses should hold regardless of the initial level of proactive behavior, as we focused on activated affective experiences before and after being proactive.

Another promising aspect future research could explore is whether other's responses and reactions to proactive behavior might be especially meaningful for employees due to the greater role of psychological ownership, as proactive behavior is a self-initiated and self-directed behavior (Cangiano \& Parker, 2016). In this regard, the regulation of one's emotions represents an important psychological resource (Law et al., 2004), which may also serve as a boundary condition of the effects of proactive behavior on well-being outcomes. More specifically, in the face of negative reactions from others, being able to regulate negative emotions resulting from proactive behavior could help to increase positive well-being outcomes. This effect likely results from better emotion regulation skills minimizing the likelihood of engaging in passionate and impulsive proactive behaviors (Kunnanatt, 2004), as well as an increased likelihood that others will positively perceive the given proactive behavior (Cangiano et al., 2017). Moreover, employees high in emotion regulation skills should be better able to cope with potential temporary setbacks or negative reactions, as well as possibly resulting negative emotions in response to their proactive behavior (Zacher \& Kooij, 2017).

\section{Conclusion}

The present study investigated the effects of proactive behavior on within-day changes in positive and negative well-being outcomes, conditional upon between-person differences in organizational tenure and emotion regulation skills. Our results show that between-person differences in emotion regulation skills interact with proactive 
behavior to predict within-day changes in emotional work fatigue, such that the effects of proactive behavior on within-day changes in emotional work fatigue are positive for employees with low emotion regulation skills. Based upon these results, organizations may take steps to increase their employees' emotion regulation skills. Moreover, our supplementary analyses revealed two interactions between between-person differences in organizational tenure and activated positive and negative affect in predicting withinday changes in proactive behavior, such that the experience of either positive or negative activated affect at work is associated with reductions in proactive behavior across the workday among employees with lower organizational tenure.

Data Availability (Data Transparency) Data is available upon request.

Code Availability (Software Application or Custom Code) Code is available upon request.

Funding Open Access funding enabled and organized by Projekt DEAL.

\section{Declarations}

All procedures performed in this study that involved human participants were in accordance with the ethical standards of the institutional research committee and with the 1964 Helsinki declaration and its later amendments or comparable ethical standards.

Conflict of Interest The authors declare that they have no conflict of interest.

Open Access This article is licensed under a Creative Commons Attribution 4.0 International License, which permits use, sharing, adaptation, distribution and reproduction in any medium or format, as long as you give appropriate credit to the original author(s) and the source, provide a link to the Creative Commons licence, and indicate if changes were made. The images or other third party material in this article are included in the article's Creative Commons licence, unless indicated otherwise in a credit line to the material. If material is not included in the article's Creative Commons licence and your intended use is not permitted by statutory regulation or exceeds the permitted use, you will need to obtain permission directly from the copyright holder. To view a copy of this licence, visit http://creativecommons.org/licenses/by/4.0/.

\section{References}

Aickin, M. (2009). Dealing with change: Using the conditional change model for clinical research. The Permanente Journal, 13(2), 80. https://doi.org/10.7812/tpp/08-070.

Andrew, Y. (2015). What we feel and what we do: Emotional capital in early childhood work. Early Years, 35(4), 351-365. https://doi.org/10.1080/09575146.2015.1077206.

Arslan, R. C., Tata, C. S., \& Walther, M. P. (2018). formr: A study framework allowing for automated feedback generation and complex longitudinal experience sampling studies using R. https://doi.org/10. 5281/zenodo.1345615.

Ashford, S. J., \& Cummings, L. L. (1985). Proactive feedback seeking: The instrumental use of the information environment. Journal of Occupational and Organizational Psychology, 58(1), 67-79. https://doi.org/10.1111/j.2044-8325.1985.tb00181.x.

Ashford, S. J., Rothbard, N. P., Piderit, S. K., \& Dutton, J. E. (1998). Out on a limb: The role of context and impression management in selling gender-equity issues. Administrative Science Quarterly, 43(1), $23-57$. https://doi.org/10.2307/2393590. 
Baltes, P. B., \& Staudinger, U. M. (2000). Wisdom: A metaheuristic (pragmatic) to orchastrate mind and virtue toward excellence. American Psychologist, 55(1), 122-136. https://doi.org/10.1037/0003-066X.55. 1.122 .

Barsade, S. G., \& Gibson, D. E. (2007). Why does affect matter in organizations? Academy of Management Perspectives, 21(1), 36-59. https://doi.org/10.5465/amp.2007.24286163.

Bates, D., Mächler, M., Bolker, B., \& Walker, S. (2014). Fitting linear mixed-effects models using lme4. Journal of Statistical Software, 67, 1-48. https://doi.org/10.18637/jss.v067.i01.

Bindl, U. K., \& Parker, S. K. (2012). Affect and employee proactivity: A goal-regulatory perspective. In Experiencing and managing emotions in the workplace (pp. 225-254). Emerald.

Bizzi, L. (2017). Network characteristics: When an individual's job crafting depends on the jobs of others. Human Relations, 70(4), 436-460. https://doi.org/10.1177/0018726716658963.

Bolger, N., \& Laurenceau, J. P. (2013). Intensive longitudinal methods: An introduction to diary and experience sampling research. Guilford Press.

Bolino, M. C., \& Turnley, W. H. (2005). The personal costs of citizenship behavior: The relationship between individual initiative and role overload, job stress, and work-family conflict. Journal of Applied Psychology, 90(4), 740. https://doi.org/10.1037/0021-9010.90.4.740.

Bolino, M. C., Valcea, S., \& Harvey, J. (2010). Employee, manage thyself: The potentially negative implications of expecting employees to behave proactively. Journal of Occupational and Organizational Psychology, 83(2), 325-345. https://doi.org/10.1348/096317910X493134.

Brislin, R. W. (1970). Back-translation for cross-cultural research. Journal of Cross-Cultural Psychology, 1(3), 185-216. https://doi.org/10.1177/135910457000100301.

Burris, E. R. (2012). The risks and rewards of speaking up: Managerial responses to employee voice. Academy of Management Journal, 55(4), 851-875. https://doi.org/10.5465/amj.2010.0562.

Cangiano, F., \& Parker, S. K. (2016). Proactivity for mental health and well-being (1st ed.): John Wiley \& Sons.

Cangiano, F., Bindl, U. K., \& Parker, S. K. (2017). The 'hot' side of proactivity: Exploring an affect-based perspective on proactivity in organizations. In S. K. Parker \& U. K. Bindl (Eds.), Proactivity at work: Making things happen in organizations. Taylor \& Francis/Routledge.

Cangiano, F., Parker, S. K., \& Yeo, G. B. (2018). Does daily proactivity affect well-being? The moderating role of punitive supervision. Journal of Organizational Behavior, 40(1), 59-72. https://doi.org/10.1002/ job.2321.

Charles, S. T. (2010). Strength and vulnerability integration: A model of emotional well-being across adulthood. Psychological Bulletin, 136(6), 1068-1091. https://doi.org/10.1037/a0021232.

Claes, R., \& Van Loo, K. (2011). Relationships of proactive behaviour with job-related affective well-being and anticipated retirement age: An exploration among older employees in Belgium. European Journal of Ageing, 8(4), 233-241. https://doi.org/10.1007/s10433-011-0203-7.

Cottingham, M. D. (2016). Theorizing emotional capital. Theory and Society, 45(5), 451-470. https://doi.org/ 10.1007/s11186-016-9278-7.

Crant, J. M. (2000). Proactive behavior in organizations. Journal of Management, 26(3), 435-462. https://doi. org/10.1177/014920630002600304.

Demerouti, E., Bakker, A. B., Nachreiner, F., \& Schaufeli, W. B. (2001). The job demands-resources model of burnout. Journal of Applied Psychology, 86(3), 499-512. https://doi.org/10.1037/0021-9010.86.3.499.

Den Hartog, D. N., \& Belschak, F. D. (2007). Personal initiative, commitment and affect at work. Journal of Occupational and Organizational Psychology, 80(4), 601-622. https://doi.org/10.1348/ $096317906 \times 171442$.

Dunford, B. B., Shipp, A. J., Boss, R. W., Angermeier, I., \& Boss, A. D. (2012). Is burnout static or dynamic? A career transition perspective of employee burnout trajectories. Journal of Applied Psychology, 97(3), 637. https://doi.org/10.1037/a0027060.

Dutton, J. E., \& Ashford, S. J. (1993). Selling issues to top management. Academy of Management Review, 18(3), 397-428. https://doi.org/10.5465/AMR.1993.9309035145.

Dutton, J. E., Ashford, S. J., O'Neill, R. M., \& Lawrence, K. A. (2001). Moves that matter: Issue selling and organizational change. Academy of Management Journal, 44(4), 716-736. https:/doi.org/10.2307/ 3069412.

Erdogan, B., \& Bauer, T. N. (2005). Enhancing career benefits of employee proactive personality: The role of fit with jobs and organizations. Personnel Psychology, 58(4), 859-891. https://doi.org/10.1111/j.17446570.2005.00772.x.

Fay, D., \& Hüttges, A. (2016). Drawbacks of proactivity: Effects of daily proactivity on daily salivary cortisol and subjective well-being. Journal of Occupational Health Psychology, 22(4), 429-442. https://doi.org/ 10.1037/ocp0000042. 
Fay, D., \& Sonnentag, S. (2002). Rethinking the effects of stressors: A longitudinal study on personal initiative. Journal of Occupational Health Psychology, 7(3), 221-234. https://doi.org/10.1037/10768998.7.3.221.

Fay, D., \& Sonnentag, S. (2012). Within-person fluctuations of proactive behavior: How affect and experienced competence regulate work behavior. Human Performance, 25(1), 72-93. https://doi.org/10.1080/ 08959285.2011 .631647$.

Finkel, S. E. (2008). Linear panel analysis. In S. Menard (Ed.), Handbook of longitudinal research: Design, measurement, and analysis. Academic Press.

Fisher, C. D., \& To, M. L. (2012). Using experience sampling methodology in organizational behavior. Journal of Organizational Behavior, 33(7), 865-877. https://doi.org/10.1002/job.1803.

Frese, M. (2000). The changing nature of work. In N. Chmiel (Ed.), Introduction to work and organizational psychology (pp. 424-439). Blackwell.

Frese, M., \& Fay, D. (2001). Personal initiative: An active performance concept for work in the 21st century. Research in Organizational Behavior, 23, 133-187. https://doi.org/10.1016/S0191-3085(01)23005-6.

Frese, M., Fay, D., Hilburger, T., Leng, K., \& Tag, A. (1997). The concept of personal initiative: Operationalization, reliability and validity in two German samples. Journal of Organizational and Occupational Psychology, 70(2), 139-161. https://doi.org/10.1111/j.2044-8325.1997.tb00639.x.

Fritz, C., \& Sonnentag, S. (2009). Antecedents of day-level proactive behavior: A look at job stressors and positive affect during the workday. Journal of Management, 35(1), 94-111. https://doi.org/10.1177/ 0149206307308911.

Frone, M. R., \& Tidwell, M.-C. O. (2015). The meaning and measurement of work fatigue: Development and evaluation of the three-dimensional work fatigue inventory (3D-WFI). Journal of Occupational Health Psychology, 20(3), 273. https://doi.org/10.1037/a0038700.

Gabriel, A. S., Podsakoff, N. P., Beal, D. J., Scott, B. A., Sonnentag, S., Trougakos, J. P., \& Butts, M. M. (2019). Experience sampling methods: A discussion of critical trends and considerations for scholarly advancement. Organizational Research Methods, 22(4), 969-1006. https://doi.org/10.1177/ 1094428118802626.

Gagné, M., \& Deci, E. L. (2005). Self-determination theory and work motivation. Journal of Organizational Behavior, 26(4), 331-362. https://doi.org/10.1002/job.322.

Geldhof, G. J., Preacher, K. J., \& Zyphur, M. J. (2014). Reliability estimation in a multilevel confirmatory factor analysis framework. Psychological Methods, 19(1), 72. https://doi.org/10.1037/a0032138.

Gerhardt, M., Ashenbaum, B., \& Newman, W. R. (2009). Understanding the impact of proactive personality on job performance: The roles of tenure and self-management. Journal of Leadership \& Organizational Studies, 16(1), 61-72. https://doi.org/10.1177/1548051809334192.

Ghitulescu, B. E. (2018). Psychosocial effects of proactivity: The interplay between proactive and collaborative behavior. Personnel Review, 47(2), 294-318. https://doi.org/10.1108/pr-08-2016-0209.

Grant, A. M. (2013). Rocking the boat but keeping it steady: The role of emotion regulation in employee voice. Academy of Management Journal, 56(6), 1703-1723. https://doi.org/10.5465/amj.2011.0035.

Grant, A. M., \& Ashford, S. J. (2008). The dynamics of proactivity at work. Research in Organizational Behavior, 28, 3-34. https://doi.org/10.1016/j.riob.2008.04.002.

Greenglass, E. R., \& Fiksenbaum, L. (2009). Proactive coping, positive affect, and well-being: Testing for mediation using path analysis. European Psychologist, 14(1), 29-39. https://doi.org/10.1027/1016-9040. 14.1.29.

Griffin, M. A., Neal, A., \& Parker, S. K. (2007). A new model of work role performance: Positive behavior in uncertain and interdependent contexts. Academy of Management Journal, 50(2), 327-347. https://doi.org/ 10.5465/AMJ.2007.24634438.

Gross, J. J. (1998). The emerging field of emotion regulation: An integrative review. Review of General Psychology, 2(3), 271-299. https://doi.org/10.1037/1089-2680.2.3.271.

Gross, J. J., \& Thompson, R. A. (2007). Emotion regulation: Conceptual foundations. In J. J. Gross (Ed.), Handbook of emotion regulation (pp. 3-26). Guilford press.

Gross, S., Meier, L. L., \& Semmer, N. K. (2013). Latent growth modeling applied to diary data: The trajectory of vigor across a working week as an illustrative example. In A. B. Bakker \& K. J. Daniels (Eds.), A day in the life of a happy worker (pp. 114-131). PsychologyPress.

Highhouse, S., \& Gillespie, J. Z. (2009). Do samples really matter that much? In C. E. Lance \& R. J. Vandenberg (Eds.), Statistical and methodological myths and urban legends: Doctrine, verity and fable in the organizational and social sciences (pp. 247-265). Routledge.

Hirschfeld, R. R., Thomas, C. H., \& Bernerth, J. B. (2011). Consequences of autonomous and team-oriented forms of dispositional proactivity for demonstrating advancement potential. Journal of Vocational Behavior, 78(2), 237-247. https://doi.org/10.1016/j.jvb.2010.09.001. 
Hobfoll, S. E. (1989). Conservation of resources: A new attempt at conceptualizing stress. American Psychologist, 44(3), 513-524. https://doi.org/10.1037/0003-066X.44.3.513.

Howell, J. M., \& Boies, K. (2004). Champions of technological innovation: The influence of contextual knowledge, role orientation, idea generation, and idea promotion on champion emergence. The Leadership Quarterly, 15(1), 123-143. https://doi.org/10.1016/j.leaqua.2003.12.008.

Jordan, P. J., Ashkanasy, N. M., \& Hartel, C. E. J. (2002). Emotional intelligence as a moderator of emotional and behavioral reactions to job insecurity. Academy of Management Review, 27(3), 361-372. https://doi. org/10.5465/amr.2002.7389905.

Kammeyer-Mueller, J., Wanberg, C., Rubenstein, A., \& Song, Z. (2013). Support, undermining, and newcomer socialization: Fitting in during the first 90 days. Academy of Management Journal, 56(4), 1104-1124. https://doi.org/10.5465/amj.2010.0791.

Kanfer, R., \& Kantrowitz, T. M. (2002). Emotion regulation: Command and control of emotion in work life. In R. G. Lord, R. J. Klimoski, \& R. Kanfer (Eds.), Emotions in the workplace: Understanding the structure and role of emotions in organizational behavior (pp. 433-472). Jossey-Brass.

Kish-Gephart, J. J., Detert, J. R., Treviño, L. K., \& Edmondson, A. C. (2009). Silenced by fear: The nature, sources, and consequences of fear at work. Research in Organizational Behavior, 29, 163-193. https:// doi.org/10.1016/j.riob.2009.07.002.

Kunnanatt, J. T. (2004). Emotional intelligence: The new science of interpersonal effectiveness. Human Resource Development Quarterly, 15(4), 489-495. https://doi.org/10.1002/hrdq.1117.

Law, K. S., Wong, C. S., \& Song, L. J. (2004). The construct and criterion validity of emotional intelligence and its potential utility for management studies. Journal of Applied Psychology, 89(3), 483-496. https:// doi.org/10.1037/0021-9010.89.3.483.

Liu, W., Tangirala, S., Lee, C., \& Parker, S. K. (2019). New directions for exploring the consequences of proactive behaviors: Introduction to the special issue. Journal of Organizational Behavior, 40(1), 1-4. https://doi.org/10.1002/job.2334.

Parker, S. K. (2000). From passive to proactive motivation: The importance of flexible role orientations and role breadth self-efficacy. Applied Psychology, 49(3), 447-469. https://doi.org/10.1111/1464-0597. 00025.

Parker, S. K., \& Bindl, U. K. (2017). Proactivity at work: Making things happen in organizations. Routledge.

Parker, S. K., \& Liao, J. (2016). Wise proactivity: How to be proactive and wise in building your career. Organizational Dynamics, 3(45), 217-227. https://doi.org/10.1016/j.orgdyn.2016.07.007.

Parker, S. K., \& Wang, Y. (2015). Helping people to 'make things happen': A framework for proactivity at work. International Coaching Psychology Review, 10(1), 62-75.

Parker, S. K., Williams, H. M., \& Turner, N. (2006). Modeling the antecedents of proactive behavior at work. Journal of Applied Psychology, 91(3), 636-652. https://doi.org/10.1037/0021-9010.91.3.636.

Parker, S. K., Bindl, U. K., \& Strauss, K. (2010). Making things happen: A model of proactive motivation. Journal of Management, 36(4), 827-856. https://doi.org/10.1177/0149206310363732.

Parker, S. K., Wang, Y., \& Liao, J. (2019). When is proactivity wise? A review of factors that influence the individual outcomes of proactive behaviors. Annual Review of Industrial and Organisational Psychology, 6(1). https://doi.org/10.1146/annurev-orgpsych-012218-015302.

Parrish, B. P., Zautra, A. J., \& Davis, M. C. (2008). The role of positive and negative interpersonal events on daily fatigue in women with fibromy- algia, rheumatoid arthritis, and osteoarthritis. Health Psychology, 27, 694-702. https://doi.org/10.1037/0278-6133.27.6.694.

Pingel, R., Fay, D., \& Urbach, T. (2019). A resources perspective on when and how proactive work behaviour leads to employee withdrawal. Journal of Occupational and Organizational Psychology, 92(2). https:// doi.org/10.1111/joop.12254.

Podsakoff, P. M., MacKenzie, S. B., Lee, J.-Y., \& Podsakoff, N. P. (2003). Common method biases in behavioral research: A critical review of the literature and recommended remedies. Journal of Applied Psychology, 88(5), 879-903. https://doi.org/10.1037/0021-9010.88.5.879.

Raudenbush, S. W., \& Bryk, A. S. (2002). Hierarchical linear models: Applications and data analysis methods (2nd ed.). Sage.

Rich, B. L., LePine, J. A., \& Crawford, E. A. (2010). Job engagement: Antecedents and effects on job performance. Academy of Management Journal, 53(3), 617-635. https://doi.org/10.5465/AMJ.2010. 51468988.

Rothbard, N. P. (2001). Enriching or depleting? The dynamics of engagement in work and family roles. Administrative Science Quarterly, 46(4), 655-684.

Schaufeli, W. B., Salanova, M., González-Romá, V., \& Bakker, A. B. (2002). The measurement of burnout and engagement: A two sample confirmatory factor analytic approach. Journal of Happiness Studies, 3, 71-92. 
Schwall, A. R. (2012). Defining age and using age-relevant constructs. In J. W. Hedge \& W. C. Borman (Eds.), The Oxford handbook of work and aging (pp. 169-186). Oxford University Press.

Seo, M.-G., \& Hill, N. S. (2005). Understanding the human side of merger and acquisition: An integrative framework. The Journal of Applied Behavioral Science, 41(4), 422-443. https://doi.org/10.1177/ 0021886305281902.

Shockley, K. M., Ispas, D., Rossi, M. E., \& Levine, E. L. (2012). A meta-analytic investigation of the relationship between state affect, discrete emotions, and job performance. Human Performance, 25(5), 377-411. https://doi.org/10.1080/08959285.2012.721832.

Snijders, T. A. B., \& Bosker, R. J. (2012). Multilevel analysis: An introduction to basic and advanced multilevel modeling. SAGE.

Sonnentag, S. (2003). Recovery, work engagement, and proactive behavior: A new look at the interface between nonwork and work. Journal of Applied Psychology, 88(3), 518-528. https://doi.org/10.1037/ 0021-9010.88.3.518.

Sonnentag, S. (2015). Dynamics of well-being. Annual Review of Organizational Psychology and Organizational Behavior, 2(1), 261-293. https://doi.org/10.1146/annurev-orgpsych-032414-111347.

Sonnentag, S., \& Starzyk, A. (2015). Perceived prosocial impact, perceived situational constraints, and proactive work behavior: Looking at two distinct affective pathways. Journal of Organizational Behavior, 36(6), 806-824. https://doi.org/10.1002/job.2005.

Sonnentag, S., Binnewies, C., \& Mojza, E. J. (2010). Staying well and engaged when demands are high: The role of psychological detachment. Journal of Applied Psychology, 95(5), 965-976. https://doi.org/10. $1037 / \mathrm{a} 0020032$.

Starzyk, A., Sonnentag, S., \& Albrecht, A.-G. (2018). The affective relevance of suggestion-focused and problem-focused voice: A diary study on voice in meetings. Journal of Occupational and Organizational Psychology, 91(2), 340-361. https://doi.org/10.1111/joop.12199.

Strauss, K., \& Parker, S. K. (2014). Effective and sustained proactivity in the workplace: A self-determination theory perspective. In M. Gagné (Ed.), The Oxford handbook of work engagement, motivation, and selfdetermination theory (pp. 50-72). Oxford University Press.

Strauss, K., Parker, S. K., \& O'Shea, D. (2017). When does proactivity have a cost? Motivation at work moderates the effects of proactive work behavior on employee job strain. Journal of Vocational Behavior, 100, 15-26. https://doi.org/10.1016/j.jvb.2017.02.001.

Tesluk, P. E., \& Jacobs, R. R. (1998). Toward an integrated model of work experience. Personnel Psychology, 51(2), 321-355. https://doi.org/10.1111/j.1744-6570.1998.tb00728.x.

Thomas, J. P., Whitman, D. S., \& Viswesvaran, C. (2010). Employee proactivity in organizations: A comparative meta-analysis of emerging proactive constructs. Journal of Occupational and Organizational Psychology, 83(2), 275-300. https://doi.org/10.1348/096317910X502359.

Tornau, K., \& Frese, M. (2013). Construct clean-up in proactivity research: A meta-analysis on the nomological net of work-related proactivity concepts and their incremental validities. Applied psychology: an international review, 62(1), 44-96. https://doi.org/10.1111/j.1464-0597.2012.00514.x.

Vecchio, R. P. (2007). It's not easy being green: Jealousy and envy in the workplace. In G. R. Ferris (Ed.), Research in personnel and human resources management. JAI Press.

Wang, H., \& Li, J. (2015). How trait curiosity influences psychological well-being and emotional exhaustion: The mediating role of personal initiative. Personality and Individual Differences, 75, 135-140. https://doi. org/10.1016/j.paid.2014.11.020.

Warr, P., Bindl, U. K., Parker, S. K., \& Inceoglu, I. (2014). Four-quadrant investigation of job-related affects and behaviours. European Journal of Work and Organizational Psychology, 23(3), 342-363. https://doi. org/10.1080/1359432X.2012.744449.

Watson, D., Clark, L. A., \& Tellegen, A. (1988). Development and validation of brief measures of positive and negative affect: The PANAS scales. Journal of Personality and Social Psychology, 54(6), 10631070. https://doi.org/10.1037/0022-3514.54.6.1063.

Weigelt, O., Syrek, C. J., Schmitt, A., \& Urbach, T. (2018). Finding peace of mind when there still is so much left undone-A diary study on how job stress, competence need satisfaction, and proactive work behavior contribute to work-related rumination during the weekend. Journal of Occupational Health Psychology, 24(3), 373-386. https://doi.org/10.1037/ocp0000117.

Wolsink, I., Den Hartog, D. D., Belschak, F. D., \& Oosterwijk, S. (2019). Do you feel like being proactive today? Trait-proactivity moderates affective causes and consequences of proactive behavior. PLoS One, 14(8). https://doi.org/10.1371/journal.pone.0220172.

Wright, T. A., \& Cropanzano, R. (2000). Psychological well-being and job satisfaction as predictors of job performance. Journal of Occupational Health Psychology, 5(1), 84-94. https://doi.org/10.1037/10768998.5.1.84. 
Xanthopoulou, D., Bakker, A. B., \& Ilies, R. (2012). Everyday working life: Explaining within-person fluctuations in employee well-being. Human Relations, 65(9), 1051-1069. https://doi.org/10.1177/ 0018726712451283 .

Zacher, H., \& Kooij, D. T. A. M. (2017). Aging and proactivity. In S. K. Parker \& U. K. Bindl (Eds.), Proactivity at work: Making things happen in organizations. Taylor \& Francis/Routledge.

Zacher, H., Schmitt, A., Jimmieson, N. L., \& Rudolph, C. W. (2019). Dynamic effects of personal initiative on engagement and exhaustion: The role of mood, autonomy, and support. Journal of Organizational Behavior, 40(1), 38-58. https://doi.org/10.1002/job.2277.

Zohar, D. (1999). When things go wrong: The effect of daily work hassles on effort, exertion and negative mood. Journal of Occupational and Organizational Psychology, 72(3), 265-283. https://doi.org/10.1348/ 096317999166671.

Zohar, D., Tzischinski, O., \& Epstein, R. (2003). Effects of energy availability on immediate and delayed emotional reactions to work events. Journal of Applied Psychology, 88(6), 1082-1093. https://doi.org/10. 1037/0021-9010.88.6.1082.

Publisher's Note Springer Nature remains neutral with regard to jurisdictional claims in published maps and institutional affiliations.

\section{Affiliations}

\section{Clarissa Bohlmann ${ }^{1} \cdot$ Cort W. Rudolph ${ }^{2} \cdot$ Hannes Zacher ${ }^{1}$}

1 Institute of Psychology - Wilhelm Wundt, Leipzig University, Neumarkt 9-19, 04109 Leipzig, Germany

2 Department of Psychology, Saint Louis University, St. Louis, MO, USA 